\title{
Error Analysis of Passive Voice Employed by University Students' in Writing Lab Reports: A Case Study of Sudan University of Science and Technology (SUST) Students' at Faculty of Sciences, Chemistry Department
}

\author{
Osama Yousif Ibrahim Abualzain ${ }^{1}$ \\ ${ }^{1}$ English Department, Faculty of Sciences and Arts, Albaha University, Almandaq, Kingdom of Saudi Arabia \\ Correspondence: Osama Yousif Ibrahim Abualzain, English Department, Faculty of Sciences and Arts, Albaha \\ University, Almandaq, Kingdom of Saudi Arabia.
}

Received: April 22, 2019 Accepted: June 20, 2019 Online Published: June 22, 2019

doi: 10.5539/elt.v12n7p153 URL: https://doi.org/10.5539/elt.v12n7p153

\begin{abstract}
The study aims at analyzing errors made by Sudan University of Science and Technology students' at faculty of Sciences-Chemistry Department in employing passive voice in writing lab reports. The study focuses precisely on identifying the types of errors occurred in using passive voice and the reasons behind these errors. Descriptive qualitative method is adopted and applied to obtain and process the gathered data. To run this study and to collect reliable data, thirty chemical students are chosen randomly as the subject of the study. Samples of the students' lab reports are collected and analyzed. The collected data is analyzed according to the Dulay et al. (1982) Surface Strategy Taxonomy model. Teachers' questionnaire is also used to find out the sources of the students' errors from the teachers' point of view. The findings of the study reveals that the majority of the students' errors are categorized as omission and misinformation whereas additions and misordering errors are fewer and unconsidered. According to the teachers, these errors are attributed to the interference of the mother tongue, lack of knowledge and carelessness of the students.
\end{abstract}

Keywords: error, error analysis, Sudan University of Science and Technology students, passive voice, lab report

\section{Introduction}

Writing skill is one of the productive skills in all languages. It is considered as a challenging task for learners. According to Hayes and Flower (1980), writing is one of the most important skills for educational success, but also one of the most complex skills to be mastered. Heaton (1975) states that "writing skills are complex and sometimes difficult to teach, requiring grammatical, rhetorical devices, conceptual and judgmental elements mastery".

University students in science fields, who run lab experiments, tend to write lab reports to explain the process and the results of the experiments. The traditional method of writing lab reports is employing passive voice form. Chistopher S. Lobban \& Maria Schefter (2017) think that passive voice form is part of the scientific point of view, the whole process is observed and events are recorded objectively as possible, avoiding personal bias by removing individuality. They confirm that using the passive voice also clarifies procedures and descriptions so they can be easily reproduced and compared.

According to (Choomthong, 2011), passive voice is the grammatical construction in which the noun working as the subject of a sentence, clause or verb is affected by the action of a verb or being acted upon by the verb. The noun working as the grammatical subject is typically the recipient of the action denoted by the verb rather than the agent, and may be used to avoid assigning responsibility to the doer.

Eli Hinkel (2004) argues that the usage of passive forms is common in academic writing, and advanced learners are expected to produce written texts that use passive forms but they often do not use passive verb phrases in correct forms.

Writing is employed for a number of different functions. These different types of writing are identified as text types. Anderson (1998) classifies the text into two main kind, factual texts which inform, instruct or persuade by giving facts and information and literary texts which entertain or elicit an emotional response by using language 
to create mental images. Lab report gives scientific facts and information about experiments and observation process. Therefore, we can categorize lab report as a text report since Anderson (1998) sees that the text report presents information about something, as it is and it is a result of systematic observation and analysis.

According to the points mentioned above about the importance of passive voice in writing lab reports, it becomes incumbent for chemical students to master the usage of passive voice to write well-formed lab reports and to avoid errors that can disturb the whole lab writing reports.

It is a kind of unfairness to look at language errors made by learners negatively. Errors are unescapable phenomenon among languages producer because non-native speakers have a certain limit that can reach to the target language. We can look at the language errors made by learners as a supporting technique that can be employed by teachers to design suitable remedial programs to help learners.

\subsection{Aims of the Study}

The study aims to fulfill the following objectives:

a) Presenting the difficulties encountered by chemical students in employing passive voice in writing lab reports.

b) Exploring the different types of errors committed by the students.

c) Finding out the sources of errors made by the students.

d) Shedding light on the importance of writing lab reports correctly.

\subsection{Hypothesis of the Study}

a) Chemical students at Sudan University of Sciences and Technology face difficulties in using passive voice in writing lab reports.

b) Most errors are omission and misinformation.

c) These errors are attributed to the interference of the mother, lack of knowledge and carelessness of the students.

\section{Methodology}

\subsection{Participants}

The participants of this study are thirty students at Sudan University of Science and Technology, Faculty of Sciences -Chemistry department in the first semester of the academic year 2018-2019. The students are studying English language as a required subject for two credit hours. The content of the English language course includes the study of the four language skills equally without focusing on a certain area.

\subsection{Material}

Collecting reliable data is the backbone of any study. The collecting data tools employed in this study are.

a) Writing lab report

Under the consultant and supervision of the chemical teachers, the students are asked to write a lab report of an experiment that they have run which entitled (Behaviour of Solids on Warming). Since the strategy of writing lab report is using passive voice form, the students are asked to write the report in passive voice.

b) Teachers' questionnaire

To find out the sources of errors made by the students, fifteen university teachers are consulted and asked about the reasons that stand behind these errors because they are closer to their students.

\section{Discussion}

According to Yang, Wefen (2010), the limited knowledge of the EFL students often make them committ errors in their writings. Yet, many researchers have acknowledged that making errors in producing English in writing is a common issue for all students learning English whose mother tongue is other than English. To give a complete picture of the case, it is crucial for the benefit of the study to touch the following areas:

\subsection{Writing Lab Report}

According to Simanek (1999) a lab report communicates your experimental results to other people. The quality of your written report will often determine how your experiment will be evaluated. Chistopher and Maria (2017) argue that the main reason for writing a lab report or scientific paper is to communicate the results of a scientific study to the public (or your teacher). Keeping this purpose in mind, there are some important things that should be considered when writing lab report is processed. 
Concise language that clearly communicates what should be said. Scientists like to get straight to the facts without any distractions, so there is no need for the kind of "flowery" language that might be used in a short story, poem, or personal essay. The sentences should provide enough detail so the reader knows what happened, but not so much detail that it gets overwhelming. Another important point about lab reports is that they should usually be written in third person, past tense. This means personal pronouns should not be used "I" or "we." Moreover, all the procedures used in the study should be written about as if they happened in the past. It can be a little awkward writing in the "passive voice" like this because most English classes teach that this style of writing is incorrect. But in science, impersonal and objective language is commonly used. Some scientists are not as concerned about this rule as they used to be, but it may be required for lab reports to be written in this way.

\subsection{Error Analysis}

According to J. Richard et al. (2002), an error is the use of a word, speech act or grammatical items in such a way it seems imperfect and significant of an incomplete learning (184). Brown (2000) defined error as "a noticeable deviation from the adult grammar of the native speaker, reflects the competence of the learner" (p. 217). Ellis (1994) sees that errors are gaps in a learner's knowledge Richard and Schmidt (2002) believe that error analysis is the study and analysis of the errors made by second language learners.

Ellis (1985) thinks that it is odd to focus on what learners get wrong rather than on what they get right. He adds that learners' errors are beneficial in helping teachers as well as the learners themselves. They help teachers to know what errors learners make and help the learners to self-correct their errors. Corder (1967), debates that learners' errors are important for learners themselves, errors are vital and adds that errors can be regarded as a device the learner uses in order to learn.

\subsection{Types of Errors}

J. Richard et al., (2002) divide learners' errors into different classes as follows:

a) Overgeneralizations: errors that occur when the speaker applies a grammatical rule in cases where it doesn't apply. Richard et al, (2002) mentioned that they are caused "by extension of target language rules to inappropriate context." (P.185). This kind of errors have been committed while dealing with regular and irregular verbs, as well as the application of plural forms. E.g. (foot $==$ foots rather than teeth) and (he goes $==$ he goed rather than went).

b) Simplifications: Resulted from learners producing simpler linguistic forms than those found in the target language, in other words, learners attempt to be linguistically creative and produce their own poetic sentences, they may succeed in doing it, but it is not necessary. This kind of errors is committed through both of omission and addition.

Examples:

1. Spelling: omission of silent letters:

$$
\text { nife (= knife), weit (weight) }
$$

\section{Grammar:}

1) Omission:

He was ${ }^{\wedge}$ good student.

They ${ }^{\wedge}$ genius scientists.

2) Addition:

The man he works for Aramco, is my uncle.

Both the boys and the girls they can study together.

c) Developmental errors: This kind of errors is somehow part of the overgeneralizations. They result of normal pattern of development, such as (cut = cuted) and (bring = bringed), it indicates that the learner has started developing their linguistic knowledge and fail to reproduce the rules they have lately been exposed to in target language learning.

d) Induced errors: Known as transfer of training, errors caused by misleading teaching examples, teachers, sometimes, unconditionally, explain a rule without highlighting the exceptions or the intended message they would want to convey. J. Richard et al. (2002) provided an example that occurs at the level of teaching prepositions and particularly "at" where the teacher may hold up a box and say "I am looking at the box", the students may understand that "at" means' "under", they may later utter "the cat is at the table" instead of the cat is under the 
table.

e) Errors of avoidance: These errors occur when the learner fails to apply certain target language rules just because they are thought of to be too difficult.

f) Errors of overproduction: In the early stages of language learning, learners are supposed to have not yet acquired enough linguistic knowledge which enable them to use the finite rules of the target language in order to produce infinite structures, most of the time, beginners overproduce, in such a way, they frequently repeat a particular structure.

Brown (2000) attributes learners' errors to two main sources. First, the interference of the mother tongue which is considered as negative one in a broad sense. The second resource of learners' errors is the systematic knowledge of an L2 that is independent of both the learner's L1 and the target language. Bryant, (1984) claims that there are two kinds of errors in language learning i.e. interlingual errors (L1) and intrallingual errors (L2). Interlingual errors were errors resulted from one's mother tongue's intrusion; while intralingual errors were errors resulted from one's misinterpretation or overgeneralization of English grammar rules.

Wilkins, D (1972) divides interference to two different kinds: positive and negative. If the interference reveals similarities in structure between the two languages, it is called positive interference or 'facilitation, but if the interference shows dissimilarities in structure between the two languages it is called negative interference.

\subsection{Passive Voice Notion}

Peters, Pam (2004), confirm that the passive voice is a grammatical voice. The noun or noun phrase that would be the object of a corresponding active sentence (such as "Our troops defeated the enemy") appears as the subject of a sentence or clause in the passive voice ("The enemy was defeated by our troops").

The subject of a sentence or clause featuring the passive voice typically denotes the recipient of the action (the patient) rather than the performer (the agent). Verbs in the passive voice in English are formed using several parts: the usual construction uses the auxiliary verbs to be or to get together with the past participle of the main verb. Therefore, the passive voice is used as a strategy that allows language users to avoid mentioning the agent.

Fowler (2015) argue that agentless passives were once common in scientific writing, where the agent may be irrelevant.

e.g. The mixture was heated to $300^{\circ} \mathrm{C}$.

The passive voice is used more frequently in scientific writing than in other prose, where it is relatively rare. A statistical study of a variety of periodicals found a maximum incidence of 13 percent passive constructions.

The linguist Geoffrey Pullum (2011) sees that the passive is not unattractive feature exclusively to bad writing, it's a useful construction often needed for clear expression, and every good writer uses it.

Passive receives criticism in hiding responsibility of the doer by omitting the agent, but the passive can be employed to emphasize the agent. Some writers have preferred placing the agent at the end of a clause or sentence to give it greater emphasis:

The enemy was killed by the soldier.

\subsection{Data Analysis}

Data analysis is considered the backbone to any study. Judd, Charles and, McCleland, Gary (1989) assert that analysis denotes to breaking a whole into its separate components for individual examination. Data analysis is a process for obtaining raw data and converting it into information useful for decision-making by users. Data are collected and analyzed to answer questions, test hypotheses or disprove theories.

After collecting the data, the analysis of data was run as follow:

a) Writing lab report

To find out the types of the students' errors, the students have to write a lab report after running the experiment in the lab. Since the doer of the action is not important in writing lab report, passive voice is the suitable form that can be employed to serve our purpose. The students have to write a lab report entitled: Behaviour of Solids on Warming.

The performance of the students is classified, checked and analyzed according to Dulay's Surface Strategy Taxonomy Model. The procedure consists of thirteen sentences. The investigation reveals that the students' sentences are not well formed, and each sentence has at least one error related to passive voice form. Totally, there are four hundreds and twelve errors in the sentences. The following table shows the types and the number 
of errors in each category.

Table 1. The types and number of students' errors

\begin{tabular}{|c|c|c|c|c|c|c|c|c|c|c|c|c|c|c|}
\hline \multirow[t]{2}{*}{ Types of Errors } & \multicolumn{14}{|c|}{ Number of errors in each sentences } \\
\hline & 1 & 2 & 3 & 4 & 5 & 6 & 7 & 8 & 9 & 10 & 11 & 12 & 13 & Total \\
\hline \multirow[t]{2}{*}{ Omission } & 13 & 14 & 16 & 15 & 8 & 14 & 12 & 11 & 14 & 17 & 11 & 15 & 14 & 174 \\
\hline & $3.15 \%$ & $3.39 \%$ & $3.88 \%$ & $3.64 \%$ & $1.94 \%$ & $3.39 \%$ & $2.91 \%$ & $2.66 \%$ & $3.39 \%$ & $4.12 \%$ & $2.66 \%$ & $3.64 \%$ & $3.39 \%$ & $42.23 \%$ \\
\hline \multirow[t]{2}{*}{ Addition } & 2 & 1 & 3 & 3 & 2 & 2 & 1 & 2 & 1 & 3 & 2 & 2 & 1 & 25 \\
\hline & $0.48 \%$ & $0.24 \%$ & $0.72 \%$ & $0.72 \%$ & $0.48 \%$ & $0.48 \%$ & $0.24 \%$ & $0.48 \%$ & $0.24 \%$ & $0.72 \%$ & $0.48 \%$ & $0.48 \%$ & $0.24 \%$ & $6.06 \%$ \\
\hline \multirow[t]{2}{*}{ Misinformation } & 12 & 15 & 19 & 21 & 11 & 17 & 14 & 13 & 17 & 22 & 14 & 11 & 9 & 195 \\
\hline & $2.91 \%$ & $3.64 \%$ & $4.61 \%$ & $5.09 \%$ & $2.66 \%$ & $4.12 \%$ & $3.39 \%$ & $3.15 \%$ & $4.12 \%$ & $5.33 \%$ & $3.39 \%$ & $2.66 \%$ & $2.18 \%$ & $47.33 \%$ \\
\hline \multirow[t]{2}{*}{ Misordering } & 2 & 1 & 2 & 2 & 1 & 2 & 1 & 1 & 1 & 2 & 1 & 1 & 1 & 18 \\
\hline & $0.48 \%$ & $0.24 \%$ & $0.48 \%$ & $0.48 \%$ & $0.24 \%$ & $0.48 \%$ & $0.24 \%$ & $0.24 \%$ & $0.24 \%$ & $0.48 \%$ & $0.24 \%$ & $0.24 \%$ & $0.24 \%$ & $4.36 \%$ \\
\hline
\end{tabular}

Table 1 shows the types and number of errors in each sentences. The total errors committed by the students in writing the lab report are four hundreds and twelve divided into four types of errors. The errors that are labelled as omission are 174 , which equals $42.23 \%$ of the total errors. In many sentences the students omitted the verb to be e.g. (Heat the lid for about 3 minutes) written as (The lid heated for about three minutes). Addition errors are 25 ones that is $6.06 \%$ of the whole errors. Here the students repeated the noun e.g. (Light the candle) written as (The candle it is lit). On one hand, misinformation errors have the lion share in the number of errors made by the students. There are 195 errors that shape around $47.33 \%$ of the total errors. The students use one grammatical form in the place of another e.g. (Raise the burner when necessary to melt more samples) written as ( The burner was raised when necessary to melt more samples). On the other hand, misordering errors are the least ones. Only 18 errors are classified as misordering ones, which is $4.36 \%$. The students here put the words in a wrong order e.g. (Slowly heat the lid with the burner flame) written by the students as (The lid slowly is heated with the burner flame).

b) Teachers' questionnaire

To find out the sources of learners' errors, a well formed teachers' questionnaire was designed and piloted. The reliability and validity of the questionnaire were checked, and then the questionnaire was distributed to fifteen teachers. The qualitative variables employed in the study ranging from Strongly agree, Agree, Not sure, Disagree to Strongly disagree.

Table 2. Teachers' questionnaire

\begin{tabular}{|c|c|c|c|c|c|c|}
\hline \multirow[t]{2}{*}{ No. } & \multirow[t]{2}{*}{ Statement } & \multicolumn{5}{|c|}{ Variables } \\
\hline & & S.A & $\mathbf{A}$ & $\mathbf{N}$ & $\mathbf{D}$ & S.D \\
\hline \multirow[t]{2}{*}{ 1- } & \multirow[t]{2}{*}{ Writing skill is one of the most difficult language skills. } & 11 & 4 & 0 & 0 & 0 \\
\hline & & $73.33 \%$ & $26.66 \%$ & & & \\
\hline \multirow[t]{2}{*}{ 2- } & \multirow{2}{*}{$\begin{array}{l}\text { Students generally commit errors when writing in passive voice } \\
\text { form. }\end{array}$} & & 2 & 1 & 2 & 1 \\
\hline & & $60.00 \%$ & $13.33 \%$ & $6.66 \%$ & $13.33 \%$ & $6.66 \%$ \\
\hline \multirow[t]{2}{*}{ 3- } & \multirow{2}{*}{$\begin{array}{l}\text { Passive voice form is a common writing technique in writing lab } \\
\text { report. }\end{array}$} & 10 & 1 & 0 & 2 & 2 \\
\hline & & $66.66 \%$ & $6.66 \%$ & & $13.33 \%$ & $13.33 \%$ \\
\hline \multirow[t]{2}{*}{ 4- } & \multirow[t]{2}{*}{ Chemical students at SUST face difficulties in writing lab report. } & 10 & 3 & 0 & 2 & 0 \\
\hline & & $66.66 \%$ & $20.00 \%$ & & $13.33 \%$ & \\
\hline \multirow[t]{2}{*}{ 5- } & \multirow{2}{*}{$\begin{array}{l}\text { Students commit errors due to the negative interference of the } \\
\text { mother tongue. }\end{array}$} & 8 & 4 & 1 & 1 & 1 \\
\hline & & $53.33 \%$ & $26.66 \%$ & $6.66 \%$ & $6.66 \%$ & $6.66 \%$ \\
\hline
\end{tabular}




\begin{tabular}{|c|c|c|c|c|c|c|}
\hline \multirow[t]{2}{*}{ 6- } & \multirow[t]{2}{*}{ Lack of knowledge stands behind students' writing errors. } & 12 & 1 & 1 & 1 & \multirow[t]{2}{*}{0} \\
\hline & & $80.00 \%$ & $6.66 \%$ & $6.66 \%$ & $6.66 \%$ & \\
\hline \multirow[t]{2}{*}{ 7- } & \multirow{2}{*}{$\begin{array}{l}\text { Students make errors in writing lab report because they } \\
\text { careless. }\end{array}$} & are 11 & 2 & 0 & 0 & 2 \\
\hline & & $73.33 \%$ & $13.33 \%$ & & & $13.33 \%$ \\
\hline
\end{tabular}

* S.A = Strongly Agree /; * A = Agree /; $\mathrm{N}=$ Not Sure /; * D = Disagree /; * S.D = Strongly Disagree.

Table 2 shows the responses of the teachers towards identifying the sources of errors committed by the chemical students at SUST in writing lab report. All the teachers confirm strongly that writing skill is difficult. About $73 \%$ of the teachers see that passive voice form is suitable in writing lab report and the majority (86\%) argue that chemical students at SUST encounter difficulties in writing lab report. The teachers attribute these errors to the interference of the mother tongue $(80 \%)$. The teachers observe that lack of knowledge is one of the considered factors that stand behind students' errors. The majority of the teachers $(86 \%)$ express their dissatisfaction of the students' carelessness when writing lab report.

\section{Results}

The findings of the study emphasizes that the students are still struggling in mastering writing skills as general. By investigating and analyzing the errors made by the chemical students at faculty of Sciences at SUST when writing lab report in passive voice form, it becomes clear for us that even university students are still suffering and far from free errors writing.

The analysis of the students' writings reveals that the omission and misordering are the majority types of errors that the students made, this support the hypothesis of the study. Regarding the teachers' questionnaire, the results shows that the teachers' point of view towards the sources of students' errors is logical. The teachers clearly attribute these errors to the interference of the mother tongue, lack of knowledge and the carelessness of the students. Students suffer from negative interference and many of them see that they did not receive explicit training in using passive voice. Moreover, a considerable amount of students think that the structure of the sentence is not important comparing to the scientific fact included in the report. This point of view strengthens the hypothesis that the students are careless when dealing with sentence structure.

The study opens the gate for further researchers to touch other aspects in this area. This study unveils the errors made by the students in writing lab report when employing passive voice form. Therefore, researchers can investigate errors made by L2 learners in using prepositions, connectors etc.

\section{References}

Anderson, M., \& Kathy, A. (1998). Text Types in English. Australia: Macmillan.

Brown. (2000). Principles of Language Learning and Teaching (4th ed.). New York: Longman press.

Bryant, W. H. (1984). Typical Errors in English made by Japanese ESL Students. JALT Journal, 6, 1-18.

Choomthong, D. (2011). A case study of learning English passive of Thai EFL learners: Difficulties and learning strategies. The Asian conference on language learning official proceedings (pp. 74-87). Retrieved from http://iafor.org/archives/offprints/acl12011offprints/ACLL2011_0083.pdf

Christopher, S. L., \& Maria, S. (2017). Writing Undergraduate Lab Reports (2nd ed.). Cambridge University Press.

Eli, H. (2004). Tense, aspect and the passive voice in L1 and L2 academic texts. Language Teaching Research, 8(1), 5-29. https://doi.org/10.1191/1362168804lr132oa

Ellis, R. (1994). The Study of Second Language Acquisition. Oxford University Press.

Ellis, R. (1985). Understanding Second Language Acquisition. Oxford University Press.

Fowler, H. W. (2015). Fowler's Dictionary of Modern English Usage. Oxford University Press.

Geoffrey, K. P. (2011). The passive in English. Language Log.

Hayes, J. R., \& Flower, L. S. (1980). Identifying the organization of writing processes. In L. W. Gregg, \& E.R. Steinberg (Eds.), Cognitive processes in writing (pp. 3-30). Hillsdale, N.J.: Lawrence Erlbaum Associates.

Heaton, J. B. (1975). Writing English Language Test. London: Longman.

Judd, C., \& McCleland, G. (1989). Data Analysis. Harcourt Brace Jovanovich. 
Peters, P. (2004). The Cambridge Guide to English Usage. Cambridge University Press. https://doi.org/10.1017/CBO9780511487040

Richards, J. C., \& Schmidt, R. (2002). Dictionary of Language Teaching Applied Linguistics. Pearson Education Limited. London: Longman.

Simanek, D. E. (1999). Laboratory records and reports. Retrieved January 18, 2007, from http://www.lhup.edu/ dsimanek/reports.htm

Wilkins, D. (1972). Linguistics in Language Teaching. London: Edward Arnold.

Yang, W. F. (2010). A Tentative Analysis of Errors in Language Learning and Use. Journal of Language Teaching and Research, 1(3), 266-268. https://doi.org/10.4304/j1tr.1.3.266-268

\section{Appendix}

Appendix (A)

Writing lab report

Behaviour of Solids on Warming Experiment

The procedure of the experiment:

1. Place a steel can lid on an iron ring attached to a ring stand.

2. Adjust the height of the ring until the lid is about 8 centimeters above the candle.

3. Place on the lid, equally spaced near the edge, small, approximately equal amounts of silver chloride, candle wax, sulfur, lead, tin, copper wire, and steel wool.

4. Place the candle wax, sulfur, and silver chloride in a separate depression in the lid.

5. Light the candle.

6. Adjust the ring height until the tip of the flame is about $4 \mathrm{~cm}$ directly below the center of the lid.

7. Heat the lid for about 3 minutes.

8. Record the observations.

9. Pay particular attention to the melting behavior and order.

10. Remove the candle and adjust the height of the iron ring about $20 \mathrm{~cm}$ above the top of a burner.

11. Slowly heat the lid with the burner flame.

12. Raise the burner when necessary to melt more samples.

13. Record the observations.

Appendix (B)

Teachers' questionnaire

\begin{tabular}{|c|c|c|c|c|c|c|}
\hline \multirow[t]{2}{*}{ No. } & \multirow[t]{2}{*}{ Statement } & \multicolumn{5}{|c|}{ Variables } \\
\hline & & S.A & $\mathbf{A}$ & $\mathbf{N}$ & D & S.D \\
\hline 1- & Writing skill is one of the most difficult language skills. & & & & & \\
\hline 2- & Students generally commit errors when writing in passive voice form. & & & & & \\
\hline 3- & Passive voice form is a common writing technique in writing lab report. & & & & & \\
\hline 4- & Chemical students at SUST face difficulties in writing lab report. & & & & & \\
\hline 5- & Students commit errors due to the negative interference of the mother tongue. & & & & & \\
\hline 6- & Lack of knowledge stands behind students' writing errors. & & & & & \\
\hline 7- & Students make errors in writing lab report because they are careless. & & & & & \\
\hline
\end{tabular}

* S.A = Strongly Agree /; * A = Agree /; * N = Not Sure /; * D = Disagree /;* S.D = Strongly Disagree. 


\section{Copyrights}

Copyright for this article is retained by the author(s), with first publication rights granted to the journal.

This is an open-access article distributed under the terms and conditions of the Creative Commons Attribution license (http://creativecommons.org/licenses/by/4.0/). 